\title{
Estudo de impacto de vizinhança: a experiência do festival Caldas Country Show em Caldas Novas, Goiás
}

\author{
Neighborhood impact study: the experience of Caldas Country \\ Show in Caldas Novas - GO
}

Obede Rodrigues Alves ${ }^{[a]}$, Otniel Alencar Bandeira ${ }^{[b]}$, Antônio Pasqualetto ${ }^{[b]}$, Ycarim Melgaço Barbosa ${ }^{[b]}$

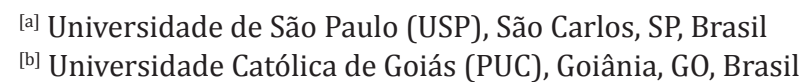

\section{Resumo}

Caldas Novas destaca-se por ser um complexo turístico hidrotermal que atrai milhares de pessoas de todas as partes do Brasil e do mundo. Na cidade, são realizados, com frequência, grandes eventos, dos quais o mais famoso deles é o Caldas Country Show, que é considerado o maior festival de música sertaneja de Goiás. Devido à falta de exigência de instrumentos de planejamento urbano para realização desse evento, a população local sofria com o impacto urbano causado pelo festival desde a sua primeira edição, em 2006. No entanto, apenas em 2012 os impactos que atingiam vários aspectos da sustentabilidade da cidade obtiveram repercussão nacional, fato que levou o Ministério Público (MP) a exigir a apresentação do Estudo de Impacto de Vizinhança (EIV). A finalidade do presente artigo é verificar a opinião dos residentes e dos comerciantes, que se localizam na área de influência direta, sobre o Caldas Country Show. Procura-se verificar também se, após a elaboração do EIV, houve melhorias significativas no evento. Os dados secundários foram levantados a partir de uma pesquisa exploratória qualitativa, e os dados primários, a partir da aplicação de questionários com perguntas estruturadas a residentes e comerciantes de Caldas Novas nos anos de 2012 e de 2013. É indubitável que o EIV cooperou para o bom desempenho do evento em sua oitava edição (2013), na qual os fatos ocorridos na edição anterior não se repetiram após a elaboração do estudo.

Palavras-chave: Impacto urbano. Planejamento. Sustentabilidade. Turismo. Vizinhança.

ORA é engenheira Ambiental; Mestra em Desenvolvimento e Planejamento Territorial pela Pontifícia Universidade Católica de Goiás - PUC Goiás; Doutoranda em Ciências da Engenharia Ambiental pela Universidade de São Paulo - USP, e-mail: alves. obede@gmail.com

OAB é discente do Mestrado em Desenvolvimento e Planejamento Territorial pela Pontifícia Universidade Católica de Goiás PUC Goiás, e-mail: otnielalencar@gmail.com

AP é engenheiro Agrônomo; Doutor em Fitotecnia; Coordenador do Programa de Mestrado em Desenvolvimento e Planejamento Territorial - MDPT da Pontifícia Universidade Católica de Goiás - PUC Goiás, e-mail: profpasqualetto@gmail.com YMB é bacharel em Direito; Doutor em Geografia pela Universidade de São Paulo - USP; Docente do Programa de Mestrado em Desenvolvimento e Planejamento Territorial - MDPT da Pontifícia Universidade Católica de Goiás - PUC Goiás, e-mail: ycarim@gmail.com 


\section{Abstract}

Caldas Novas stands out as a hydrothermal resort that attracts thousands of people from all parts of Brazil and the world. In the city, they are carried out with great frequency events being the most famous Caldas Country Show considered the largest country music festival of Goias. Due to lack of demand for urban planning instruments for the event, the local population suffered from the urban impact the festival since its first edition in 2006. However, only in 2012 the impacts that affected many aspects of city sustainability achieved national repercussions fact that led the prosecution to demand the presentation of the Neighborhood Impact Study. The purpose of this study is to verify the views of residents and merchants who are located in the area of direct influence on the Caldas Country Show. Wanted also check, after the preparation of the EIV, there were significant improvements in the event. Secondary data were collected from a qualitative exploratory research and primary data from the questionnaires with structured questions with residents and Caldas Novas traders in the years 2012 and 2013. There is no doubt that the EIV cooperated for good performance event in its eighth edition in 2013, and the events in the previous edition were not repeated after the preparation of the study.

Keywords: Urban impact. Planning. Sustainability. Tourism. Neighborhood.

\section{Introdução}

Uma cidade é o resultado de um produto social e de ações acumuladas. Nesse sentido, o ambiente urbano é um espaço socialmente criado. Já o espaço físico é alterado pela ação humana, a qual, com sua cultura, acarreta os efeitos da degradação (Corrêa, 2003). Inserida nesse contexto encontra-se Caldas Novas, localizada no Estado de Goiás, região Centro-Oeste do Brasil. Essa cidade destaca-se por ser um complexo turístico hidrotermal que atrai milhares de pessoas de todas as partes do Brasil e do mundo, que prestigiam suas belezas naturais e suas fontes hidrotermais (Costa, 2008).

$\mathrm{Na}$ cidade, são realizados, com frequência, grandes eventos, como o Verão Sertanejo, o Festival de Inverno e, o mais famoso, o Caldas Country Show. Este último, que teve sua primeira edição em 2006, é considerado o maior festival de música sertaneja de Goiás. Esse evento atrai turistas oriundos de mais de 600 cidades brasileiras e de diversos outros países, como Argentina, Paraguai, Uruguai e, até mesmo, os Estados Unidos.

O Caldas Country Show vem se destacando e atraindo, a cada ano, mais pessoas para Caldas Novas. No entanto, a cidade não apresenta infraestrutura urbana capaz de atender, de forma sustentável, a esse número de turistas, o que acaba gerando profundos impactos urbanos e ambientais.

Até o ano de 2012, a população local sofria com impactos de diversas ordens causados pelo evento, quais sejam: trânsito lento; excesso de barulho; vandalismo; violência; uso de drogas ilícitas; furtos e roubos; cenas impróprias em lugares públicos; falta de água; acúmulo de lixo em vias públicas; depredação do patrimônio público, entre outros. 0 impacto urbano atingia vários aspectos que envolviam a sustentabilidade.

O Poder Público municipal nunca havia solicitado um estudo prévio de impacto antes da concessão de autorização/licença para o evento. Destaca-se que o Caldas Country ocupa área superior a $100 \mathrm{mil} \mathrm{m}$, $^{2}$ atrai, como aconteceu em 2012, cerca de 60 mil pessoas em apenas dois dias de festa (Estudo de Impacto de Vizinhança Caldas Country Show, 2013) em uma cidade cuja população não ultrapassa 80 mil habitantes, segundo o Instituto Brasileiro de Geografia e Estatística (IBGE, 2014), e gera profundos impactos na infraestrutura urbana e, principalmente, na população residente.

Uma consequência da falta de exigência da aplicação de instrumentos de planejamento urbano para realização desse festival foi observada em 2012. Nesse ano, o Caldas Country teve repercussão nacional após inúmeras fotos postadas na Internet: pessoas baleadas e mortas; carros em chamas nas ruas da cidade; prática de atos sexuais em lugares públicos; exploração sexual; indivíduos pulando e dançando em cima das viaturas de polícia, entre outros atos de violência e vandalismo. Diante desse cenário, a imagem de Caldas Novas foi denegrida nacionalmente e a cidade passou a ser vista como 
um lugar sem controle social e de baixa segurança, isto é, não adequada para receber turistas.

Tendo em vista que a economia da cidade assenta-se no turismo, o Poder Público precisou tomar medidas para impedir que acontecimentos similares se repetissem. Para tanto, o Ministério Público (MP) solicitou aos organizadores do evento o Estudo de Impacto de Vizinhança (EIV) como requisito para realização do evento em 2013. Assim sendo, levantam-se os seguintes questionamentos: qual a opinião da população caldense sobre o Caldas Country Show? Na edição de 2013 do evento, houve melhorias significativas em relação à de 2012?

A partir desses questionamentos, a finalidade deste artigo é verificar a opinião dos residentes e comerciantes, que se localizam na área de influência direta, sobre o Caldas Country Show. Procura-se verificar também se, após a elaboração do EIV, houve melhorias significativas no evento.

\section{O estudo de impacto de vizinhança}

A expressão impacto de vizinhança foi criada para descrever um determinado grupo de impactos ambientais que ocorrem em áreas urbanas, consequentes da implantação e da operação de empreendimentos, e que se manifestam na área de influência de determinado empreendimento (Lollo \& Rohm, 2005).

Como consequência da adoção desse novo enfoque, surgiu a necessidade de proposição de um mecanismo de análise dos impactos de vizinhança. Tal mecanismo se configurou na forma dos EIVs. Apesar de ser instituído a partir do Estatuto da Cidade (EC) - Lei no 10.257 de 2001 (Brasil, 2001) -, o EIV já existia em algumas cidades brasileiras, com diferentes nomes, como instrumento de gestão ambiental urbana (Cymbalista, 2001). Segundo Oliveira \& Araújo (2008), essa expressão foi criada para descrever determinados impactos ambientais que ocorrem especificamente em áreas ou ambientes urbanos devido à implantação de determinados empreendimentos. Os impactos se expressam na área de influência direta e indireta de determinado empreendimento.

Conforme Coelho $(2004$, p. 23), o conceito contemporâneo de impacto de vizinhança é multifacetado e dinâmico,

[...] ultrapassa a perspectiva que o limitava às análises de alteração ou comprometimento dos usos das propriedades vizinhas, alcançando todo o cenário de um ambiente específico, neste caso o ambiente urbano - ambiente difuso lapidado pelos princípios da sustentabilidade.

Rocco (2009), com base no Código Civil de 1916 e também no atual Código Civil, esclarece que

[...] o impacto de vizinhança diria respeito ao mau uso da propriedade vizinha e seus consequentes reflexos à incolumidade físico-psíquica das pessoas vizinhas, individualmente consideradas. (Rocco, 2009, p. 107-108).

Além do EIV, o EC apresenta outro instrumento de controle e de gestão de impactos: o Estudo de Impacto Ambiental (EIA). Ambos pretendem garantir o "direito ao meio ambiente ecologicamente equilibrado" para "as presentes e futuras gerações" (Constituição Federal - Brasil, 1988), por meio da previsão de estudos de impacto para obras ou atividades potencialmente geradoras de degradação urbana e ambiental (Bassul, 2005).

O EIV é uma “[...] modalidade específica de avaliação de impacto ambiental adaptada a empreendimentos e impactos urbanos" (Sánchez, 2006, p. 88), previsto no EC como um dos instrumentos de gestão urbana que depende de regulamentação municipal. 0 art. 37 do EC explica a forma como o EIV deve ser executado:

Art. 37. 0 EIV será executado de forma a contemplar os efeitos positivos e negativos do empreendimento ou atividade quanto à qualidade de vida da população residente na área e suas proximidades, incluindo a análise, no mínimo, das seguintes questões:

I - adensamento populacional; II - equipamentos urbanos e comunitários;

III - uso e ocupação do solo; IV - valorização imobiliária; V - geração de tráfego e demanda por transporte público;

VI - ventilação e iluminação;

VII - paisagem urbana e patrimônio natural e cultural. (Brasil, 2001, p. 29-30).

0 art. 36 do EC esclarece que caberá à lei municipal definir quais empreendimentos ou atividades de natureza privada ou pública serão obrigados a apresentar o EIV para obtenção de licenças ou de autorizações para construção, ampliação e/ou funcionamento. O EC, ao estabelecer a exigência do EIV para obtenção tanto de licenças como de autorizações, expandiu as possibilidades de inclusão de empreendimentos 
e atividades, sejam fixas ou temporárias (festivais, feiras, conferências etc.) (Moraes, 2007).

De acordo com Silva \& Lollo (2013), pode-se afirmar que o EIV possui dupla finalidade, a saber: (1) intermediar a relação entre o empreendedor, a população afetada e o Poder Público municipal; (2) identificar e quantificar os impactos potenciais de determinado empreendimento ou atividade sobre a qualidade de vida da população vizinha.

Ao partir da premissa do cumprimento da função social da propriedade, a primeira finalidade do EIV é

[...] fazer a mediação entre os interesses privados dos empreendedores e o direito à qualidade urbana daqueles que moram ou transitam em seu entorno. (Saule \& Rolnik, 2001, p. 198).

No que tange à sua segunda finalidade, a análise dos casos de regulamentação e prática de licenciamento urbano revelam que a principal dificuldade enfrentada é a definição dos temas que irão compor o escopo mínimo do estudo a fim de evitar uma visão fragmentada dos efeitos causados pelo empreendimento (Oliveira \& Araújo 2008).

As conclusões do EIV podem conduzir à aprovação do empreendimento sob condições e contrapartidas ou inviabilizar o projeto. Devem-se levar em consideração os impactos resultantes da instalação do empreendimento na vizinhança sob os pontos de vistas ambiental, paisagístico, econômico e social. A partir do EIV, o Poder Público pode exigir alterações no projeto ou contrapartidas, tais como: diminuição da área construída; aumento de área permeável e áreas verdes; aumento do número de vagas para estacionamento; medidas de isolamento acústico; implantação de escolas e creches; investimento em transporte coletivo, postos de saúde, entre outros (Sundfeld, 2006).

\section{Metodologia}

\section{Caracterização da área de estudo}

O crescimento do município de Caldas Novas foi regido, principalmente, pela exploração das águas termais, a qual, por sua vez, promoveu o desenvolvimento do turismo e da rede hoteleira do município (Costa \& Silva, 2011). Observa-se, a partir da Tabela 1, a evolução da população de Caldas Novas desde 1960 até 2010.

Para implantação de toda a estrutura do Caldas Country Show, é necessária a ocupação de uma área relativamente grande. 0 local destinado ao evento encontra-se na Gleba Remanescente 5, destacada da Fazenda Serrinha, denominada Chácara Roma, correspondendo exatamente a uma área de 152.910,26 mil m² (Figura 1). As coordenadas geográficas são $17^{\circ} 43^{\prime} 32.72^{\prime \prime} \mathrm{S}$ e $48^{\circ} 37^{\prime} 29.59^{\prime \prime} 0$. A altitude do terreno é de $727 \mathrm{~m}$ (Estudo de Impacto de Vizinhança Caldas Country Show, 2013).

O Caldas Park Show foi projetado para abrigar shows de grandes dimensões. 0 local possui rede de abastecimento de água, energia elétrica, iluminação de vias pública, rede de telefonia móvel no perímetro, acesso pavimentado e sinalização.

0 raio que delimita a área de influência direta do empreendimento, estabelecido no EIV apresentado pelos organizadores, é de $1.000 \mathrm{~m}$. Dentro dessa área encontram-se muitas residências e hotéis. Apesar de o local do evento situar-se em um ponto específico da cidade, pode-se dizer que influencia todo o município, mesmo os shows ocorrendo apenas no período noturno, visto que, nos demais períodos, os turistas e os residentes circulam pela região.

\section{Material e método}

A pesquisa foi realizada na cidade de Caldas Novas, em Goiás. Por ter como objeto de estudo o Caldas Country Show, este artigo consiste em um estudo de caso. Para tanto, utilizou-se a metodologia da

Tabela 1 - Caldas Novas, Goiás: evoluc̦ão da população (1960-2010)

\begin{tabular}{ccc}
\hline Ano & Número de habitantes & Crescimento percentual \\
\hline 1960 & 5.200 & - \\
1970 & 7.200 & 38,5 \\
1980 & 9.800 & 36,1 \\
1991 & 24.900 & 154,1 \\
2001 & 49.652 & 100,1 \\
2007 & 62.204 & 28 \\
2010 & 70.463 & 11,7 \\
\hline
\end{tabular}

Fonte: Costa \& Silva (2011). 


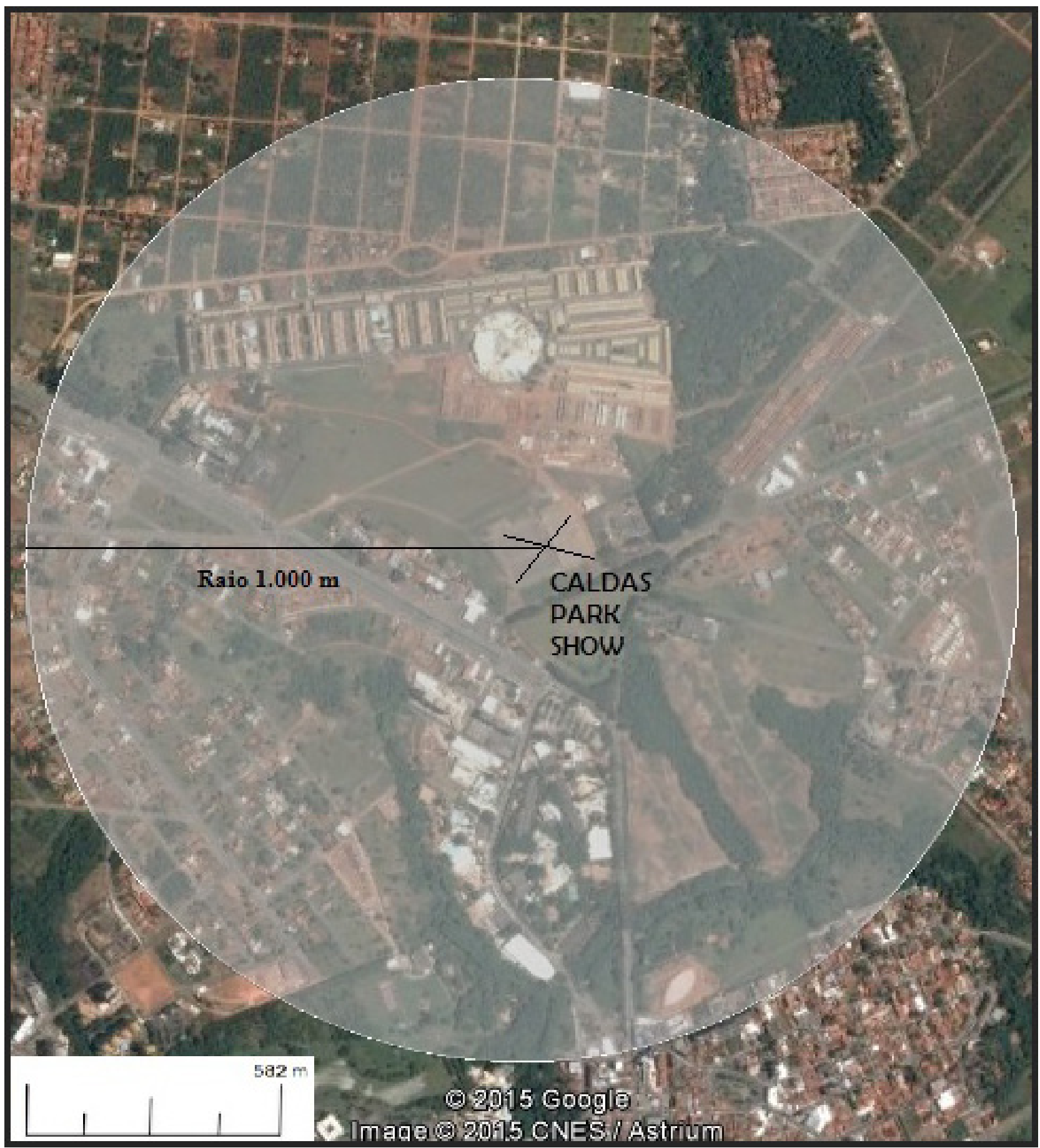

Figura 1 - Localização geográfica do Caldas Park Show, local onde ocorre o Caldas Country Show, em Caldas Novas, Goiás Fonte: Google Earth (2015), organizado por Cristiane Roldan.

avaliação pós-ocupação (APO), que tem como objetivo diagnosticar aspectos positivos e negativos do ambiente construído e de seu entorno. A APO está incluída na área de conhecimento mais abrangente, que trata das relações entre o ambiente e o comportamento. Portanto diz “[...] respeito às relações biunívocas entre o ambiente construído e o comportamento do usuário deste ambiente" (Ornstein, 1992, p. 40).

A APO é uma alternativa metodológica para avaliação de desempenho de ambientes construídos e um instrumento capaz de medir os erros e os acertos encontrados no objeto de estudo avaliado a partir 
do ponto de vista dos usuários (Lay \& Reis, 1994). Os resultados podem ser usados como novos insumos e diretrizes para futuros projetos com características semelhantes. Podem, sobretudo, ser utilizados para adaptações, renovações, reformas e reorganizações naqueles ambientes estudados (Ornstein, 1992).

Para o levantamento de dados secundários, utilizou-se como metodologia a pesquisa exploratória qualitativa, realizada por meio da leitura de livros, artigos, documentos eletrônicos, além do EIV e do Plano de Gerenciamento de Resíduos Sólidos do Caldas Country de 2013. Os dados primários foram levantados por meio da aplicação de questionários com perguntas estruturadas. Para tanto, foram elaborados dois questionários: um que foi aplicado aos residentes, e o outro, aos comerciantes de Caldas Novas. Os critérios para seleção dos entrevistados foram: (1) residir em Caldas Novas há pelo menos três anos; (2) residir ou possuir comércio dentro da área de influência direta do festival; (3) possuir idade igual ou superior a 18 anos. A quantidade de questionários aplicados representou $30 \%$ dos comércios e residências da área de influência direta.

A pesquisa foi dividida em duas etapas: a primeira se referiu à descrição dos impactos observados nas fases pré-festival, realização do festival e pós-festival, seguido das medidas adotadas pelo Estudo de Impacto de Vizinhança Caldas Country Show (2013); a segunda parte se referiu à avaliação da percepção de informantes-chave sobre a aplicabilidade do EIV por meio dos questionários.

0 primeiro questionário foi aplicado a 30 pessoas, das quais 15 eram residentes e 15 eram comerciantes, no período entre novembro e dezembro de 2012, logo após a realização da sétima edição do Caldas Country. O segundo questionário foi aplicado um ano depois, também a 30 pessoas, 15 residentes e 15 comerciantes, no período entre novembro e dezembro de 2013, logo após a oitava edição - primeira edição realizada após a apresentação e aplicação do EIV.

Foi solicitado aos entrevistados que atribuíssem notas de 0 a 10, em que as notas de 0 a 2 qualificariam o item como "péssimo", de 3 a 5, "ruim", de 6 a 7, "bom" e de 8 a 10, "ótimo". Os itens avaliados pelos entrevistados foram: geração de tráfego e demanda por transporte público (sinalização, estacionamento, congestionamento, disponibilidade e facilidade de transporte público); equipamentos urbanos e comunitários (bebedouros e banheiros públicos, lixeiras, telefone público, postos de informações, atendimento médico-hospitalar); paisagem urbana e patrimônios natural e cultural (depredação de patrimônio público e privado, limpeza de vias públicas, degradação do meio ambiente natural); uso e ocupação do solo (localização do empreendimento); segurança (atuação de policiais, bombeiros, agentes de trânsito). Foram pesquisados ainda os seguintes itens: satisfação popular, violência urbana, geração de resíduos sólidos, ruídos, impactos no trânsito, depredação de patrimônios público e particular e adensamento populacional.

Os questionários tiveram por objetivo identificar a opinião dos entrevistados sobre o Caldas Country Show. Os dados foram tabulados e os resultados expostos em tabelas, observando-se a frequência de respostas.

\section{Resultados e discussões}

O EIV é um instrumento de planejamento urbano que deve ser aplicado não apenas às edificações, indústrias e ao comércio em geral, mas, principalmente, a grandes eventos, capazes de aglomerar milhares de pessoas simultaneamente.

O EIV faz o levantamento dos impactos negativos e positivos gerados pelo evento, que devem ser observados com cuidado e classificados de acordo com as fases do evento. Os impactos observados e as medidas adotadas Estudo de Impacto de Vizinhança Caldas Country Show (2013) durante a fase pré-festival estão descritas no Quadro 1.

Durante a fase pré-festival, é importante que o EIV estabeleça limites de venda de ingressos correspondentes à capacidade da cidade (abastecimento de água, hospedagem, transporte). Ressalta-se que o processo de montagem da estrutura do evento gera muitos incômodos à vizinhança, quais sejam: barulho intenso, carga e descarga de materiais, interdições de vias públicas, entre outros.

O Quadro 2 mostra os impactos observados e as medidas adotadas durante a fase de realização do evento.

Na Figura 2, é possível observar a quantidade de pessoas nas ruas da cidade durante os dias de realização do evento. A imagem A foi produzida em agosto de 2012, em um final de semana, no período de baixa temporada na cidade. Já a imagem B foi produzida em novembro de 2012, em um final de semana, no 
Quadro 1 - Impactos observados e medidas adotadas durante a fase pré-festival do Caldas Country Show, em Caldas Novas, Goiás

\begin{tabular}{l|l}
\hline \multicolumn{1}{c}{ Impactos } & \multicolumn{1}{c}{ Fase: pré-festival } \\
\hline Fomento do comércio local. & Aquisição de parte dos alimentos e bebidas no município de Caldas Novas. \\
\hline Aumento de empregos formais e informais. & Contrataç̃ão da mão de obra no município de Caldas Novas. \\
\hline Adensamento populacional (sobrecarga na infraestrutura do município). & Venda de ingressos limitada. \\
\hline Aumento do risco de acidente de trânsito. & $\begin{array}{l}\text { Campanha em parceria com a Polícia Rodoviária e Polícia Militar para distribuição de } \\
\text { panfletos e conscientização de motoristas. }\end{array}$ \\
\hline Geração de ruídos durante o processo de montagem da estrutura. & Montagem da estrutura somente em horário comercial. \\
\hline Aumento do trânsito de carretas e caminhões durante a montagem da estrutura. & Horários e locais adequados para carga e descarga. \\
\hline
\end{tabular}

Fonte: Elaborado pelos autores a partir de dados extraídos do Estudo de Impacto de Vizinhança Caldas Country Show (2013).

Quadro 2 - Impactos observados e medidas adotadas durante a fase realização do festival Caldas Country Show, em Caldas Novas, Goiás

\begin{tabular}{|c|c|}
\hline \multicolumn{2}{|r|}{ Fase: realização do festival } \\
\hline Impactos & Medidas \\
\hline Ruídos provenientes dos shows. & Sistema de som do tipo Line Array, que restringe a emissão de som apenas ao local delimitado. \\
\hline Ruídos provenientes de sons automotivos. & $\begin{array}{l}\text { Implantação de placas de advertência na cidade; aumento do efetivo de policiais e de agentes de trânsito nos } \\
\text { dias do evento. }\end{array}$ \\
\hline Aumento da demanda por estacionamento. & $\begin{array}{l}\text { Melhoria na sinalização de trânsito, em parceria com a Superintendência Municipal de Trânsito (SMT), com } \\
\text { placas indicando locais de estacionamento (proibido e permitido); criação de estacionamentos exclusivos para os } \\
\text { participantes do evento. }\end{array}$ \\
\hline Congestionamento. & $\begin{array}{l}\text { Melhoria na sinalização de trânsito com placas indicando as principais vias de acesso ao centro da cidade, hotéis } \\
\text { e local do evento; criação de acessos alternativos ao local do festival; melhoria do transporte público coletivo; } \\
\text { identificacã̃o e sinalização de locais de parada, embarque e desembarque de ônibus, téxi e mototáxi na cidade e } \\
\text { no local do evento; disponibilização de vans gratuitas para buscar o participante no hotel e levá-lo até o local do } \\
\text { festival. }\end{array}$ \\
\hline Dificuldade de circulação de pedestres. & $\begin{array}{l}\text { Proibição de vendedores ambulantes nas imediaç̃̃es e calçadas do evento; melhoria na sinalização das faixas de } \\
\text { pedestres; implantação de semáforos de pedestres em pontos estratégicos da cidade. }\end{array}$ \\
\hline Geração de resíduos sólidos. & Elaboração e implantação do Plano de Gerenciamento de Resíduos Sólidos. \\
\hline Sobrecarga nos equipamentos de saúde. & $\begin{array}{l}\text { Disponibilização de } 2 \text { ambulâncias (UTI móvel) no local do evento, com } 4 \text { médicos, } 2 \text { enfermeiros, } 4 \text { técnicos de } \\
\text { enfermagem, } 1 \text { socorrista, } 2 \text { motoristas e } 1 \text { recepcionista para triagem. }\end{array}$ \\
\hline
\end{tabular}

Fonte: Elaborado pelos autores a partir de dados extraídos do Estudo de Impacto de Vizinhança Caldas Country Show (2013).

período de alta temporada, época em que ocorre o Caldas Country Show.

$\mathrm{Na}$ imagem A, nota-se a fluidez e a tranquilidade do trânsito em período de baixa temporada, algo típico de uma cidade interiorana. Já a imagem $B$ revela uma situação que destoa da realidade do cotidiano de Caldas Novas.

Conforme dados do Departamento Nacional de Trânsito (DENATRAN, 2014), a frota total de veículos em Caldas Novas em dezembro de 2014 era de
53.091 veículos. Durante o Caldas Country Show, a Superintendência Municipal de Trânsito - SMT (Caldas Novas, 2014) se prepara para receber um acréscimo de aproximadamente 30 mil carros (Figura 3).

0 acréscimo populacional e da frota de veículos no município, mesmo que por tempo determinado, aumenta o número de acidentes de trânsito. Segundo a SMT, que registra apenas ocorrências sem vítimas, em 2013 foram registrados, em média, 35 acidentes por mês em Caldas Novas, uma redução de aproximadamente $30 \%$ 

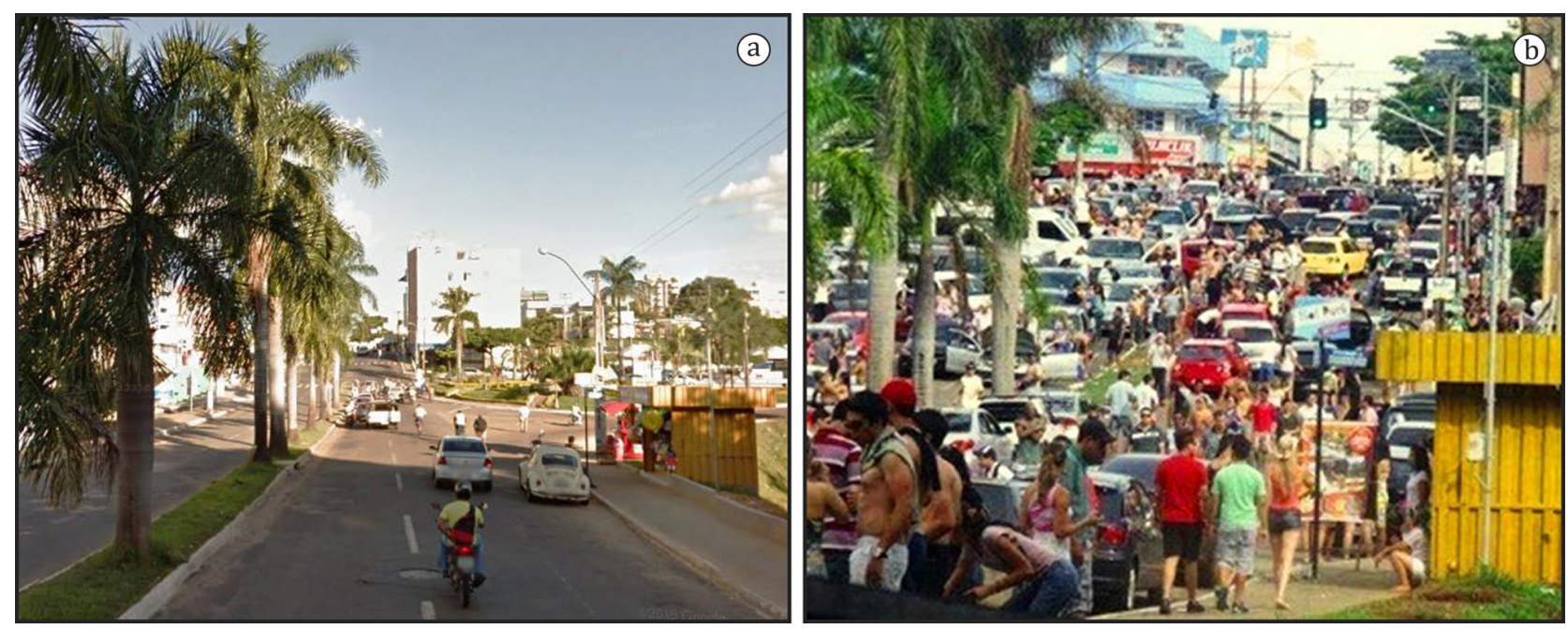

Figura 2 - (A) Trânsito na Rua do Turismo em Caldas Novas em finais de semana normais; (B) A mesma rua durante o evento Caldas Country, em Caldas Novas, Goiás, 2012

Fonte: (A) Arquivo pessoal (2012); (B) Folha de Brasilia (2013).

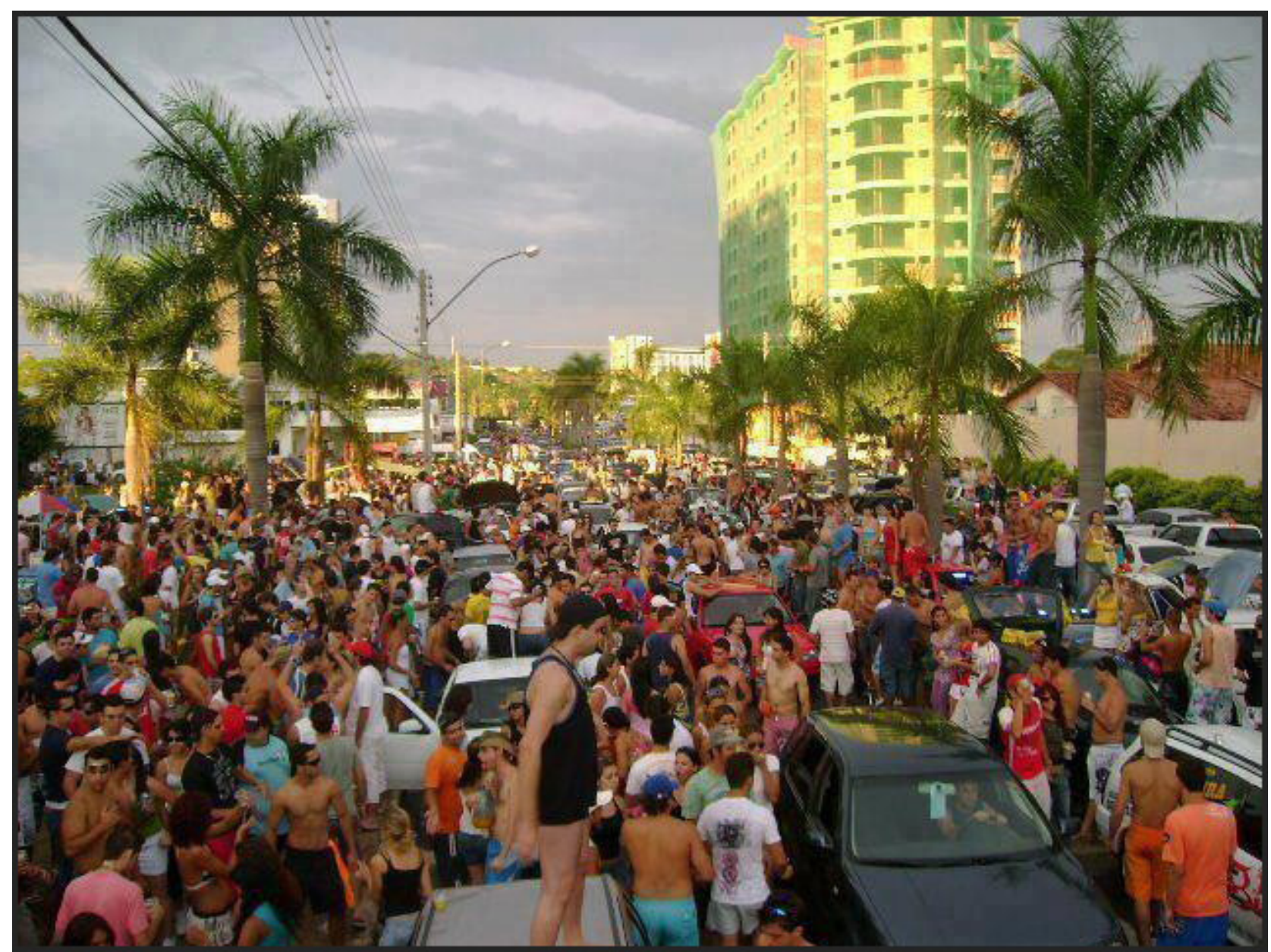

Figura 3 - Situação de uma avenida em Caldas Novas durante a realização do Caldas Country Show, em Caldas Novas, Goiás, 2012 Fonte: Jornal do Sudeste (2012). * Imagem removida do site. 
em relação a 2012 (Caldas Novas, 2014). Essa redução ocorreu devido a uma série de medidas estabelecidas pela Prefeitura Municipal, como melhoramento e implantação de novas sinalizações (horizontais e verticais) e instalação de redutores de velocidade em diversos pontos da cidade.

Levantamento realizado pelo Observatório de Mobilidade e Saúde Humana do Estado de Goiás (Goiás, 2014a) aponta os acidentes de trânsito como a segunda maior causa de óbitos registrados no Estado. Goiás apresenta índice sete vezes maior do que o nível de tolerância preconizado pela Organização das Nações Unidas (ONU) quanto à taxa de mortalidade por 10 mil veículos. 0 Estado possui também índices mais elevados do que a média nacional (Goiás, 2014a). O Quadro 3 mostra os dez municípios responsáveis por $64 \%$ das mortes no Estado por acidente de

Quadro 3 - Dez municípios do Estado de Goíás com as maiores taxas de mortalidade por acidente de transporte terrestre

\begin{tabular}{l|c}
\hline \multicolumn{1}{c|}{ Município } & $\begin{array}{c}\text { Taxa de mortalidade por acidente de } \\
\text { transporte terrestre (\%) }\end{array}$ \\
\hline Uruaçu & 50,1 \\
\hline Mineiros & 46,7 \\
\hline Catalão & 43,9 \\
\hline Anápolis & 37,5 \\
\hline Caldas Novas & $\mathbf{3 2 , 2}$ \\
\hline Aparecida & 30,2 \\
\hline Rio Verde & 29,8 \\
\hline Goiânia & 29,4 \\
\hline
\end{tabular}

Fonte: Goiás (2014a) transporte terrestre. Caldas Novas encontra-se na quinta posição, superando até mesmo as taxas de Goiânia, a capital de Goiás.

Em Goiás, são 29,9 mortes por 100 mil habitantes ou 7,4 mortes por 10 mil veículos, enquanto que, na média nacional, os números são de 20,1 mortes por 100 mil habitantes ou 6,2 óbitos por 10 mil veículos. De acordo com dados da Vigilância Epidemiológica de Violência e Acidentes da Secretaria de Estado da Saúde do Estado de Goiás (SES-GO), o número de óbitos por acidente de trânsito em 2012 foi de 2.054 e, em 2014, o custo de internação com vítimas de acidente de trânsito chegou a R \$9.024.652,02 (Goiás, 2014b).

o Quadro 4 apresenta os impactos observados e as medidas adotadas pelo Estudo de Impacto de Vizinhança Caldas Country Show (2013) durante a fase pós-festival.

A fase pós-festival exige maior atuação das Polícias Militar e Rodoviária na prevenção de acidentes de trânsito e na gestão de resíduos sólidos, para destinação ambientalmente correta dos resíduos, e da equipe de montagem, que precisa ter horários adequados para carregar caminhões e desmontar a estrutura do complexo.

\section{Avaliação do estudo de impacto de vizinhança do Caldas Country}

A opinião da população com relação aos empreendimentos construídos é bastante importante, a ponto de ela ser, segundo o EC, previamente consultada antes da implantação de atividades e/ou empreendimentos impactantes. 0 Quadro 5 apresenta a opinião da população de Caldas Novas sobre o Caldas Country nos anos de 2012 e de 2013.

Quadro 4 - Impactos observados e medidas adotadas durante a fase pós-festival Caldas Country Show, em Caldas Novas, Goiás

\begin{tabular}{l|l}
\hline \multicolumn{1}{c}{ Impactos } & \multicolumn{1}{c}{ Mase: - pós-festival } \\
\hline Aumento do risco de acidentes de trânsito. & $\begin{array}{l}\text { Campanha em parceria com a Polícia Rodoviária e Polícia Militar para distribuição de } \\
\text { panfletos e conscientização de motoristas. }\end{array}$ \\
\hline Geração de ruídos durante o processo de desmontagem da estrutura. & Desmontagem da estrutura somente em horário comercial. \\
\hline Aumento do trânsito de carretas e caminhões durante a desmontagem da estrutura. & Horários e locais adequados para carga e descarga. \\
\hline Geração de resíduos sólidos. & Elaboração e implantação do Plano de Gerenciamento de Resíduos Sólidos. \\
\hline
\end{tabular}

Fonte: Elaborado pelos autores a partir de dados extraídos do Estudo de Impacto de Vizinhança Caldas Country Show (2013). 
Quadro 5 - Comparação entre as respostas dadas pelos entrevistados sobre a realização do Caldas Country Show nos anos de 2012 e 2013, em Caldas Novas, Goiás

\begin{tabular}{|c|c|c|c|c|c|c|c|c|}
\hline \multirow{2}{*}{ Questionário } & \multicolumn{4}{|c|}{ Evento 2012} & \multicolumn{4}{|c|}{ Evento 2013} \\
\hline & Sim & $\%$ & Não & $\%$ & Sim & $\%$ & Não & $\%$ \\
\hline 1) Você concorda com o festival Caldas Country? & 25 & 83 & 5 & 17 & 27 & 90 & 3 & 10 \\
\hline 2) Você acha que 0 evento traz beneficicos para a cidade? & 29 & 97 & 1 & 3 & 28 & 93 & 2 & 7 \\
\hline 3) Você concorda com a localizaç̃o do festival? & 14 & 47 & 16 & 53 & 12 & 40 & 18 & 60 \\
\hline 4) Você está satisfeito (a) com a organizaç̦ão da cidade nos dias do evento? & 3 & 10 & 27 & 90 & 23 & 77 & 7 & 23 \\
\hline 5) Em sua opiniõo, o festival gera impactos de vizinhança? & 25 & 83 & 5 & 17 & 19 & 63 & 11 & 37 \\
\hline $\begin{array}{l}\text { 6) Você acha que o número de pessoas que o evento atrai é superior à capacidade de } \\
\text { atendimento do munićíio? }\end{array}$ & 22 & 73 & 8 & 27 & 20 & 67 & 10 & 33 \\
\hline 7) Em sua opinião, a geração de resíduos sólidos aumenta durante 0 evento? & 20 & 67 & 10 & 33 & 13 & 43 & 17 & 57 \\
\hline 8) Em sua opiniõ̃o, o festival causa perturbação (rúídos à sociedade em geral)? & 24 & 80 & 6 & 20 & 18 & 60 & 12 & 40 \\
\hline 9) Em sua opinião, os índices de violência urbana aumentam nos dias do evento? & 30 & 100 & 0 & 0 & 14 & 47 & 16 & 53 \\
\hline $\begin{array}{l}\text { 10) Você concorda que, no período do evento, o número de carros aumenta a ponto } \\
\text { de gerar congestionamentos na cidade? }\end{array}$ & 29 & 97 & 1 & 3 & 18 & 60 & 13 & 43 \\
\hline $\begin{array}{l}\text { 11) Em sua opinião, houve melhorias significativas na organizaccão da cidade durante } \\
\text { a realização do Caldas Country, edição de } 2013 \text {, em relação cos eventos anteriores? }\end{array}$ & \multicolumn{4}{|c|}{ Não aplicável } & 30 & 100 & 0 & 0 \\
\hline
\end{tabular}

Fonte: Elaborado pelos autores a partir dos questionários aplicados em 2012 e 2013.

Em 2012, quando questionados se concordavam com o festival, $83 \%$ dos entrevistados responderam que sim e 17\% responderam que não. Em 2013, 90\% concordavam e apenas $10 \%$ discordavam do evento. Nota-se que, em relação a 2012, houve, no ano de 2013, um aumento de 7\% no número de entrevistados que concordavam com o evento. Mesmo com a repercussão negativa que a edição de 2012 trouxe à cidade, os residentes e os comerciantes aprovaram a realização do Caldas Country Show. Muitos podem ser os motivos que influenciaram as respostas dos entrevistados. Segundo dados da Secretaria Estado de Gestão e Planejamento (SEGPLAN), de 1998 a 2007, Caldas Novas teve um aumento de $130 \%$ na quantidade de empregos formais no município e o seu rendimento médio dobrou no mesmo período (Tabela 2) (SEGPLAN, 2009).

O Estudo de Impacto de Vizinhança Caldas Country Show (2013) aponta como fatores positivos do evento: divulgação da cidade em mídia nacional; recolhimentos fiscais para a Prefeitura; fortalecimento do comércio local; geração de renda aos moradores da cidade sob a forma de trabalho temporário; desenvolvimento econômico local e regional; valorização imobiliária.
Com relação à oferta de trabalho temporário, o EIV destaca uma quantidade significativa de empregos durante os dias do festival (Quadro 6).

0 empreendimento Caldas Country Show localiza-se em área urbana estabelecida pelo Plano Diretor Municipal, Lei no 1829/2011, (Caldas Novas, 2011) como Zona Residencial de Média Densidade, com predomínio de uso para habitação. Em 2012, quando questionados sobre o local para a realização do evento, apenas 16 pessoas discordavam da localização. Em 2013, esse número subiu para 18.

Em 2012, a insatisfação dos entrevistados com relação à organização da cidade durante os dias do evento foi predominante - apenas três pessoas afirmaram estar satisfeitas. 0 restante mostrou insatisfação. Solicitou-se aos entrevistados insatisfeitos que apontassem alguns motivos de insatisfação.

Quando questionados se o contingente populacional atraído pelo festival era superior à capacidade do município, $73 \%$ e $67 \%$ responderam que sim em 2012 e 2013, respectivamente. Nota-se que Caldas Novas apresenta deficiência em alguns aspectos da infraestrutura básica. Sobre isso, uma das questões mais polêmicas diz respeito ao saneamento ambiental. 
Quadro 6 - Estimativa de geração de empregos temporários no Caldas Country Show, em Caldas Novas, Goiás

\begin{tabular}{l|l}
\hline \multicolumn{1}{c|}{ Atividade } & \multicolumn{1}{c}{ Quantidade de pessoas } \\
\hline Suporte emergencial de resgate (2 ambulâncias com UTI móvel) & $\begin{array}{l}4 \text { médicos, 2 enfermeiros, 4 técnicos de enfermagem, I socorrista, 2 motoristas e } 1 \text { recepcionista para } \\
\text { triagem. }\end{array}$ \\
\hline Seguranças & 400 por dia. \\
\hline Limpeza & 300 por dia. \\
\hline Recepcionistas & 60 por dia. \\
\hline Auxiliares (barman e outros) & 300 por dia. \\
\hline
\end{tabular}

Fonte: Estudo de Impacto de Vizinhança Caldas Country Show (2013).

Tabela 2 - Quantidade de empregos formais no município de Caldas Novas, Goiás, e rendimento médio no período de 1998 a 2007

\begin{tabular}{lcccccccccc}
\hline \multicolumn{10}{c}{ Emprego } \\
\hline & $\mathbf{1 9 9 8}$ & $\mathbf{1 9 9 9}$ & $\mathbf{2 0 0 0}$ & $\mathbf{2 0 0 1}$ & $\mathbf{2 0 0 2}$ & $\mathbf{2 0 0 3}$ & $\mathbf{2 0 0 4}$ & $\mathbf{2 0 0 5}$ & $\mathbf{2 0 0 6}$ & $\mathbf{2 0 0 7}$ \\
\hline $\begin{array}{l}\text { Número de empregos } \\
\text { formais }\end{array}$ & 5.647 & 6.229 & 6.733 & 7.942 & 8.536 & 9.544 & 9.912 & 11.316 & 11.786 & 13.067 \\
Rendimento Médio- RS & $\ldots$ & 438,97 & 372,68 & 394,58 & 443,38 & 510,7 & 551,8 & 594,52 & 664,49 & 718,79 \\
\hline
\end{tabular}

Fonte: SEGPLAN (2009).

De acordo com dados levantados pelo Departamento Municipal de Água e Esgoto (DEMAE) de Caldas Novas (Tabela 3), há uma carência nesse serviço, porém, ao longo dos anos, vem aumentando paulatinamente o número de ligações de esgoto e água tratada no município (DEMAE, 2009).

Concernente à saúde, observa-se, com base na Tabela 4, que a disponibilidade de leitos e hospitais teve uma oscilação em 2002 e 2003, recuperando-se a partir de 2006. Em 1996, a relação era de 1,31 leito por 1.000 habitantes e, em 2007, era de 2,1 leitos por 1.000 habitantes. Esses índices se agravam em Caldas Novas quando se considera o aumento da população flutuante no município que necessita desse tipo de serviço na alta temporada (Andrade, 2009).

Com relação aos resíduos sólidos, $67 \%$ dos entrevistados afirmaram, em 2012, que, durante o festival, esses resíduos aumentaram; em 2013, foram $43 \%$. Isso não significa que a geração de resíduos diminuiu. No entanto, na percepção dos entrevistados, houve uma queda.

Para uma boa gestão dos resíduos produzidos, foi elaborado um Plano de Gerenciamento de Resíduos Sólidos vinculado ao EVI, com estimativa de público
Tabela 3 - Quantidade de ligações de esgoto e água tratada em Caldas Novas, Goiás

\begin{tabular}{ccc}
\hline Ano & Ligações de esgoto & $\begin{array}{c}\text { Ligações de água } \\
\text { tratada }\end{array}$ \\
\hline 2002 & 5.315 & 14.546 \\
2004 & 5.879 & 16.321 \\
2005 & 7.816 & 16.679 \\
2007 & 9.499 & 19.763 \\
2008 & 9.684 & 21.147 \\
\hline
\end{tabular}

Fonte: DEMAE (2009).

de 60 mil pessoas, incluindo a mão de obra contratada para as três fases do evento (montagem, realização e desmontagem) (Plano de Gerenciamento de Resíduos Sólidos Caldas Country Show, 2013). A quantificação dos resíduos gerados pode ser observada no Quadro 7.

Com base no levantamento de dados sobre a quantidade de bebidas consumidas no evento, foi possível fazer uma estimativa de resíduos sólidos gerados, a saber: Vodka, 20 mil litros; Whisky, 10 mil litros; Refrigerante (PET 2 litros), 5 mil unidades; 
Tabela 4 - Quantidade de leitos e de hospitais em Caldas Novas, Goiás

\begin{tabular}{cccccccccccc}
\hline & \multicolumn{10}{c}{ Saúde } \\
\hline & 1996 & 1997 & 1998 & 1999 & $\mathbf{2 0 0 0}$ & $\mathbf{2 0 0 1}$ & $\mathbf{2 0 0 2}$ & $\mathbf{2 0 0 3}$ & $\mathbf{2 0 0 6}$ & $\mathbf{2 0 0 7}$ & $\mathbf{2 0 0 9}$ \\
\hline Hospitais $\left(\mathrm{n}^{0}\right)$ & 2 & 3 & 4 & 4 & 4 & 4 & 3 & 3 & 4 & 4 & 4 \\
Leitos $\left(\mathrm{n}^{0}\right)$ & 52 & 102 & 126 & 126 & 126 & 126 & 96 & 96 & 129 & 131 & 149 \\
\hline
\end{tabular}

Fonte: SEGPLAN (2003).

Quadro 7 - Classificação e quantificação de resíduos gerados durante o Caldas Country Show, em Caldas Novas, Goićs

\begin{tabular}{c|c|c}
\hline \multicolumn{2}{c}{ Classificação e quantidade de resíduos } & Quantidade \\
\hline Tipos de resíduos & Especificação & $150 \mathrm{Kg}$ \\
\hline Orgânicos & Restos de comida. & $200 \mathrm{Kg}$ \\
\hline Rejeitos & Papel higiênico, absorventes, bituca de cigarro, guardanapos usados. & $1.500 \mathrm{Kg}$ \\
\hline Recicláveis & Papéis, plásticos em geral (exceto PET de 2 litros), metais, papelão, copos descartáveis. & $21.000 \mathrm{Kg}$ \\
\hline Recicláveis & Garrafas de vidro. & $270 \mathrm{Kg}{ }^{\star \star}$ \\
\hline Recicláveis & Garrafa PET de 2 litros. & Dados indisponíveis \\
\hline Resíduos líquidos (esgoto) & Proveniente dos banheiros químicos. & \\
\hline
\end{tabular}

*Considerou-se 0 peso médio de cada garrafa de vidro de aproximadamente $700 \mathrm{~g} .{ }^{* \star}$ Considerou-se o peso da garrafa de $2 \mathrm{~L}$ de aproximadamente 54 gramas.

Fonte: Plano de Gerenciamento de Resíduos Sólidos Caldas Country Show (2013).

as cervejas não eram vendidas em lata, apenas em garrafas retornáveis. Os resíduos predominantes são recicláveis. Portanto devem ser armazenados adequadamente e destinados à cooperativa mais próxima do local (Estudo de Impacto de Vizinhança Caldas Country Show, 2013).

No que diz respeito aos resíduos sólidos, as metas estabelecidas pelo Estudo de Impacto de Vizinhança Caldas Country Show (2013) foram as seguintes:

a. utilização de 20 coletores de 240 litros para os recicláveis;

b. uso de álcool gel no banheiro para diminuir a quantidade de papel para secar as mãos;

c. utilização de vassouras de garrafas PET na limpeza;

d. destinação dos recicláveis para a cooperativa mais próxima. (Estudo de Impacto de Vizinhança Caldas Country Show, 2013, p. 25).

Os dados do Quadro 7 referem-se apenas aos resíduos gerados no espaço do evento. Não foram considerados no Estudo de Impacto de Vizinhança
Caldas Country Show (2013) os resíduos sólidos produzidos em hotéis e restaurantes da cidade. Sabe-se que o adensamento populacional em Caldas Novas durante o festival interfere significativamente na quantidade de resíduos sólidos, na geração de efluentes líquidos e no consumo de água e energia (Andrade, 2009).

O sistema definido pelo Estudo de Impacto de Vizinhança Caldas Country Show (2013) é o de coleta simples, que divide os resíduos sólidos em dois fluxos: recicláveis e não recicláveis. A opção por esse modelo, de acordo com o estudo, justifica-se pela ineficácia da segregação dos resíduos recicláveis em diversas categorias em grandes eventos, visto que, mesmo separados, seguem para o mesmo destino, as cooperativas de materiais recicláveis. Assim, duas categorias de lixeiras são instaladas: uma de cor azul, para os recicláveis, e outra de cor cinza, para os não recicláveis.

Sobre os incômodos produzidos pelo festival, $80 \%$ dos entrevistados, no ano de 2012, responderam que o Caldas Country gerava perturbação e ruídos. Em 2013, esse índice caiu para 20\%. Um dos efeitos 
negativos do evento está relacionado à poluição sonora que afeta toda a área de influência direta e indireta do empreendimento. Essa perturbação ocorre por poucas horas durante os dias de festival. Devido ao curto período de exposição ao barulho, esse impacto é considerado moderado e o grau de incômodo à vizinhança não é alto, haja vista que o sistema de som usado é do tipo Line Array (Estudo de Impacto de Vizinhança Caldas Country Show, 2013).

A regulagem adequada do som pode evitar incômodo maior aos espectadores e à vizinhança. 0 local de realização do evento também pode colaborar com a minimização do impacto sonoro. Ressalta-se que a escolha do local para implantação de eventos em cidades turísticas deve estar de acordo com o Plano Diretor e a Lei de Zoneamento Municipal.

Outro dado que merece atenção diz respeito à violência urbana. Em 2012, todos os entrevistados afirmaram que os índices de violência aumentaram nos dias do evento. 0 Quadro 8 apresenta o histórico de homicídios em Caldas Novas de 1999 a 2013.

0 Caldas Country teve a sua primeira edição em 2006. Porém não é possível estabelecer uma relação direta entre o aumento do número de óbitos por homicídio e a realização do evento na cidade. Nem mesmo é possível afirmar que, em 2012, ano em que o festival gerou polêmica, o aumento expressivo na taxa de homicídios ocorreu devido ao evento. No entanto, esses dados necessitam ser apreciados com atenção pelo Poder Público, com vistas à implantação de medidas preventivas durante o período do festival. Mesmo que o Caldas Country Show não seja o fator preponderante para o aumento dos homicídios, de alguma forma tem colaborado para tal.

Outro dado significativo levantado pela pesquisa diz respeito à existência ou não de melhorias significativas na organização da cidade durante a realização do Caldas Country Show. Em 2013, todos os entrevistados responderam que houve melhorias em relação aos anos anteriores. Os aspectos que evidenciaram essas melhorias foram: disponibilidade de banheiros químicos na cidade; aumento do número de policiais, bombeiros e agentes de trânsito; acesso ao serviço de transporte coletivo e táxi facilitado; melhoria na sinalização de vias públicas; aumento de lixeiras na cidade e no local do evento; existência de pontos de atendimento e informação ao turista.

A percepção dos entrevistados quanto às mudanças ocorridas na realização do festival (2013 em relação a 2012) foi apreendida a partir da atribuição de notas a itens previamente estabelecidos, quais sejam: geração de tráfego e demanda por transporte público; equipamentos urbanos e comunitários; paisagem urbana e patrimônio natural e cultural; uso e ocupação do solo e segurança.

Em relação ao primeiro item pesquisado, que é geração de tráfego e demanda por transporte público (Figura 4), os entrevistados avaliaram questões relacionadas à sinalização de trânsito, às vagas para estacionamento, ao congestionamento e à disponibilidade e facilidade de transporte público. Na opinião dos entrevistados, houve melhorias significativas nesse item. A partir de uma análise comparativa entre os dois anos, os resultados obtidos foram estes: em 2012, 23 atribuíram conceito péssimo para geração de tráfego; já em 2013, foram apenas 10. Em 2012, ninguém avaliou esse item como ótimo, e apenas dois entrevistados atribuíram conceito bom. Em 2013, pôde-se observar um tímido aumento do conceito ótimo e redução significativa do conceito péssimo.

Quadro 8 - Histórico de homicídios de 1999 a 2013 em Caldas Novas, Goiás

\begin{tabular}{c|c|c|c}
\hline \multirow{2}{*}{ Ano } & \multirow{2}{*}{$\begin{array}{c}\text { Número de } \\
\text { homicidios }\end{array}$} & \multicolumn{2}{|c}{$\begin{array}{c}\text { Taxa de homicídios } \\
\text { (nº óbitos/ 100 mil habitantes) }\end{array}$} \\
\cline { 3 - 4 } & & Caldas Novas & Nacional \\
\hline 1999 & 6 & 13,27 & 26,18 \\
\hline 2000 & 4 & 8,05 & 26,71 \\
\hline 2001 & 10 & 18,95 & 27,81 \\
\hline 2002 & 9 & 16,36 & 28,46 \\
\hline 2003 & 9 & 15,65 & 28,86 \\
\hline 2004 & 12 & 20,00 & 27,01 \\
\hline 2005 & 6 & 9,14 & 25,83 \\
\hline 2006 & 9 & 13,14 & 26,31 \\
\hline 2007 & 9 & 12,61 & 25,20 \\
\hline 2008 & 21 & 31,83 & 26,43 \\
\hline 2009 & 20 & 29,59 & 26,86 \\
\hline 2010 & 17 & 24,12 & 27,40 \\
\hline 2011 & 27 & 37,46 & 27,13 \\
\hline 2012 & 35 & 47,54 & 29,04 \\
\hline 2013 & 22 & $28,24$. & 26,99 \\
\hline
\end{tabular}

Fonte: DATASUS (2013). 


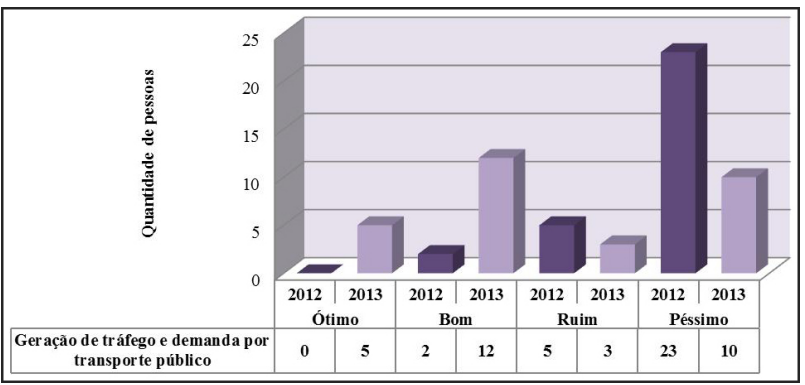

Figura 4 - Comparação de notas atribuídas pelos entrevistados (2012 e 2013) ao item geração de tráfego e demanda por transporte público durante o Caldas Country Show, em Caldas Novas, Goiás Fonte: Elaborado pelos autores.

No que se refere ao item equipamentos urbanos e comunitários (Figura 5), os entrevistados avaliaram questões como: disponibilidade de bebedouros e banheiros públicos; lixeiras; telefone público; postos de informações; atendimento médico-hospitalar. A avaliação sobre equipamentos urbanos e comunitários também apresentou melhoria significativa na percepção dos entrevistados. Em 2012, das 30 pessoas entrevistadas, 25 atribuíram conceito péssimo. Em contrapartida, em 2012, 20 pessoas atribuíram conceito ótimo.

Quanto ao item paisagem urbana (Figura 6), os entrevistados avaliaram questões concernentes à depredação de patrimônio público e privado, limpeza de vias públicas e degradação do meio ambiente natural. Em 2012, metade dos entrevistados (15) atribuiu conceito péssimo; dois entrevistados, conceito ótimo; oito, conceito bom; cinco, conceito ruim. Em 2013, houve aumento dos conceitos ótimo (sete entrevistados), bom (10 entrevistados) e ruim (oito entrevistados) e queda significativa do conceito péssimo (apenas cinco entrevistados).

Dentro do item uso e ocupação do solo (Figura 7), os entrevistados avaliaram o local de realização do festival. Observa-se que, na percepção deles, não houve mudanças significativas nos anos de 2012 e 2013. Os resultados indicam que os entrevistados demonstraram insatisfação com a localização do evento. Em 2012, 10 entrevistados atribuíram conceito bom a esse item; em 2013, foram nove. Em 2012, 10 entrevistados atribuíram conceito péssimo; em 2013, foram 13 pessoas. Importa destacar que se manteve o mesmo local para a realização do evento nos anos em que os questionários foram aplicados.

Com relação ao item segurança (Figura 8), verificou-se que os entrevistados observaram melhoria significativa

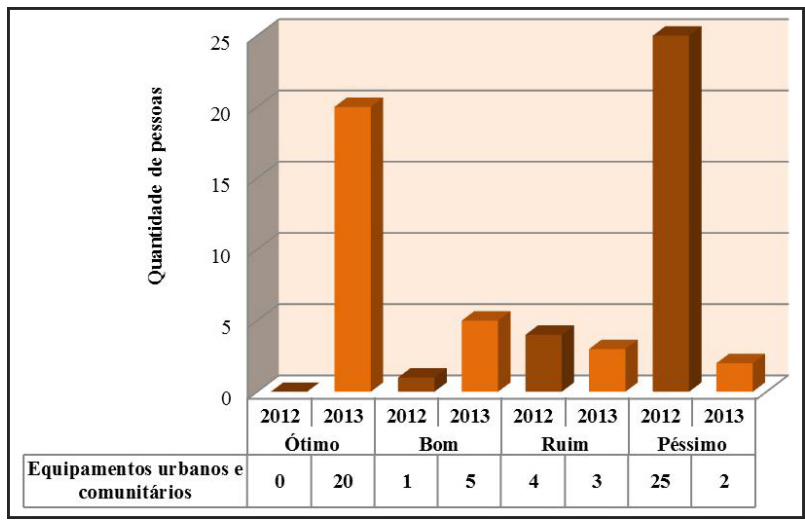

Figura 5 - Comparação de notas atribuídas pelos entrevistados (2012 e 2013) a0 item equipamentos urbanos e comunitários durante 0 Caldas Country Show, em Caldas Novas, Goiás Fonte: Elaborado pelos autores.

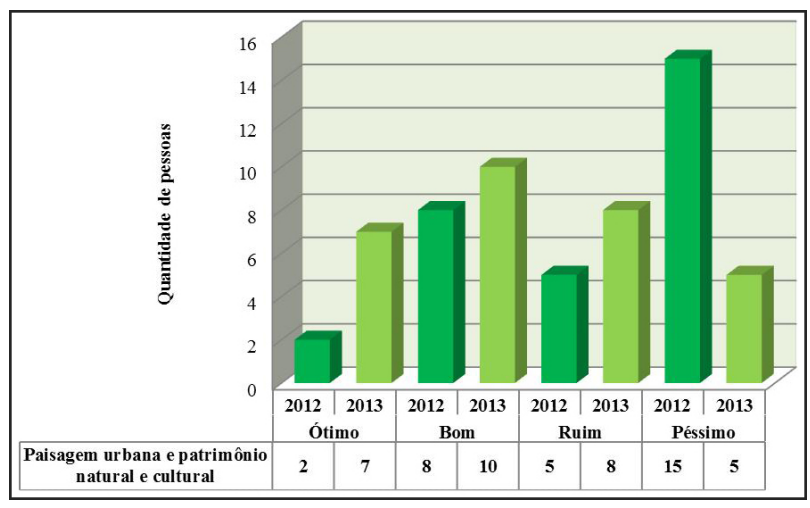

Figura 6 - Comparação de notas atribuídas pelos entrevistados (2012 e 2013) ao item paisagem urbana e patrimônio natural e cultural durante 0 Caldas Country Show, em Caldas Novas, Goiás Fonte: Elaborado pelos autores.

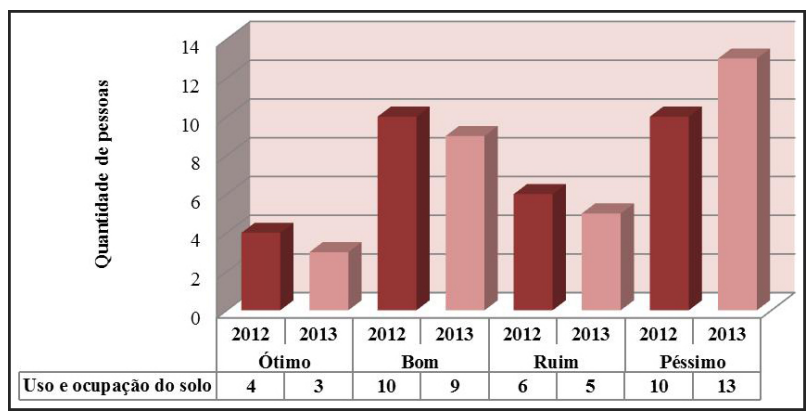

Figura 7 - Comparação de notas atribuídas pelos entrevistados (2012 e 2013) ao item uso e ocupacã̃o do solo durante o Caldas Country Show, em Caldas Novas, Goiás Fonte: Elaborado pelos autores.

entre um ano e outro nesse quesito. Em 2012, 22 entrevistados atribuíram conceito péssimo a esse item e apenas um atribuiu conceito ótimo; em 2013, a quantidade de pessoas que avaliaram a segurança como 


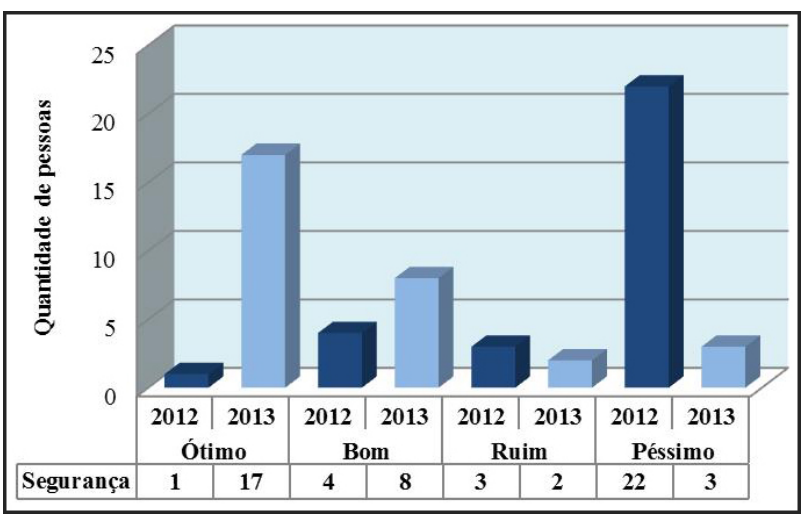

Figura 8 - Comparacãa de notas atribuídas pelos entrevistados (2012 e 2013) ao item segurança durante o Caldas Country Show, em Caldas Novas, Goićs Fonte: Elaborado pelos autores.

ótima subiu para 17, enquanto o conceito péssimo foi apontado por apenas três entrevistados. No ano de 2013, o conceito bom aumentou em relação a 2012 e o conceito ruim diminuiu.

\section{Considerações finais}

Pode-se afirmar que o EIV do Caldas Country Show promoveu o desenvolvimento do turismo ao minimizar impactos negativos à população local, apresentando-se, portanto, como instrumento adequado para a intermediação entre os interesses dos empreendedores do evento e os da população envolvida, conseguindo manter os padrões mínimos de qualidade de vida da vizinhança direta e indireta do Caldas Park Show.

É indubitável que o EIV cooperou para o bom desempenho do evento em sua oitava edição, em 2013, pois os fatos ocorridos na edição anterior não se repetiram após a elaboração do estudo. O índice de violência urbana, como furtos, estupros, depredação do patrimônio público e particular, diminuiu significativamente, sem nenhum registro de homicídio e com garantia da qualidade de vida e da segurança dos turistas e vizinhos durante todo o evento. Além disso, o município foi beneficiado com a arrecadação fiscal, e o comércio local, fortalecido.

Observa-se que órgãos responsáveis pela solicitação do EIV têm limitado sua aplicabilidade, exigindo-o apenas para empreendimentos com instalações fixas, como comércios e indústrias. No entanto, é evidente que o EIV é um forte aliado na minimização de impactos de vizinhança causados por grandes eventos, devendo ser mais explorado pelos municípios.

A associação entre o desenvolvimento urbano e a qualidade de vida, atrelados ao EIV, permite a inserção de empreendimentos fixos e de eventos provisórios no espaço urbano, valorizando tanto as atividades econômicas quanto a comunidade. Desse modo, não basta que as cidades turísticas foquem na promoção de grandes eventos; o mais importante é que os planejem e saibam como eles poderão contribuir para o desenvolvimento local e regional. Se não forem aplicados os instrumentos de planejamento urbano e ambiental nessas ocasiões, corre-se o risco de, no futuro, não haver controle e solução para os problemas sociais e urbanos da cidade.

Portanto, o EIV pode ser aplicado a outros megaeventos a fim de minimizar os impactos negativos que muitos desses causam ao meio ambiente urbano, além de potencializar benefícios econômicos locais. A experiência do município de Caldas Novas após a implantação do EIV foi positiva e pode servir de modelo para eventos em outras cidades goianas, até mesmo em cidades de outros Estados, principalmente àquelas que atraem grande quantidade de turista aos megaeventos/festivais promovidos.

\section{Referências}

Andrade, S. M. (2009). Desenvolvimento Turístico e Condições de Vida no Município de Caldas Novas - GO (Dissertação de mestrado). Faculdade Alves Faria, Goiânia.

Bassul, J. R. (2005). Estatuto da cidade. Brasília: Senado Federal.

Brasil. (1988, 5 de outubro). Constituição da República Federativa do Brasil de 1988. Brasília: Senado. Recuperado em 10 abril 2015, de http://www.planalto.gov.br/ccivil_03/ Constituicao/ConstituicaoCompilado.htm

Brasil. (2001, 7 de julho). Lei n. 10.257, de 10 de julho de 2001. Regulamenta os arts. 182 e 183 da Constituição Federal, estabelece diretrizes gerais da política urbana e dá outras providências. Brasília: Diário Oficial da União. Recuperado em 10 de abril de 2013, de http://www.planalto.gov.br/ ccivil_03/leis/leis_2001/l10257.htm

Caldas Novas. (2011, 30 de dezembro). Lei n. 1829 de 30 de dezembro de 2011. Institui a nova Política Urbana e Ambiental e o Plano Diretor do Município de Caldas Novas 
e suas diretrizes. Caldas Novas: Procuradoria Geral do Município de Caldas Novas. Recuperado em 23 de março de 2013, de http://www.caldasnovas.go.gov.br/new/ wp-content/uploads/2013/07/01_Politica_Urbana_e_ Ambiental_Do_Municipio_De_Caldas_Novas.pdf

Caldas Novas. Prefeitura Municipal. Superintendência Municipal de Trânsito. (2014). Acidentes de trânsito em Caldas Novas, 2014. Caldas Novas. Recuperado em 17 de abril de 2015, de http://www.caldasnovas.go.gov.br/ categoria/s-m-t/

Coelho, M. C. N. (2004). Impactos ambientais em áreas urbanas: teorias, conceitos e métodos de pesquisa. In A. J. T. Guerra \& S. B. Cunha. Impactos ambientais urbanos no Brasil. Rio de Janeiro: Bertrand Brasil.

Corrêa, L. R. (2003). O espaço urbano (4a ed.). São Paulo: Ática.

Costa, R. A. (2008). Zoneamento ambiental da área de expansão urbana de Caldas Novas -GO: procedimentos e aplicações (Tese de doutorado). Universidade Federal de Uberlândia, Uberlândia.

Costa, R. A., \& Silva, G. A. (2011). Avaliação da qualidade ambiental do aterro sanitário de Caldas Novas (GO). Revista Brasileira de Ciências Ambientais, 22, 1-10.

Cymbalista, R. (2001). Estudo de impacto de vizinhança. São Paulo: Dicas Polis. Recuperado em 17 de abril de 2015, de http://www.polis.org.br/uploads/634/634.pdf

Departamento de Informática do SUS - DATASUS. (2013). Óbitos por causas externas, 2013. Brasília: Ministério da Saúde. Recuperado em 10 de abril de 2015, de http:// tabnet.datasus.gov.br/cgi/deftohtm.exe?sim/cnv/ext10br.def Departamento Municipal de Água e Esgoto de Caldas Novas - DEMAE. (2009). Apurações de variáveis de ligações de redes de esgoto e água tratada. Caldas Novas: DEMAE. Recuperado em 10 de abril de 2015, de http://www. demae.go.gov.br/

Departamento Nacional de Trânsito - DENATRAN. (2014). Frota de veículos, por tipo e com placa, segundo os Municípios da Federação - DEZ/2014. Brasília: DENATRAN. Recuperado em 10 de abril de 2015, de http://denatran.gov.br/frota/ veiculos/dez/2014

Estudo de Impacto de Vizinhança Caldas Country Show. (2013). Processo no. 201300516580 (3o volume). Caldas Novas - GO: 2a Vara Cível: Fórum.
Folha de Brasília. (2013). MP vai pedir a impugnação dos documentos que permitem o Caldas Country 2013. Brasília: Folha de Brasília. Recuperado em 11 de setembro de 2014, de http://www.folhadebrasilia.com/mp-vai-pedira-impugnacao-dos-documentos-que-permitem-o-caldascountry-2013/

Goiás. Governo de Goiás. Secretaria de Meio Ambiente, Recurso Hídricos, Infraestrutura, Cidades e Assuntos Metropolitanos - SECIMA. (2014a). Observatório de Mobilidade e Saúde Humana do Estado de Goiás: Dez municípios do estado de Goiás com as maiores taxas de mortalidade por acidente de transporte terrestre. Recuperado em 11 de setembro de 2014, de http://www.secima.go.gov.br/post/ver/196839/ observatorio-da-mobilidade-e-saude-humana-omsh

Goiás. Governo de Goiás. Vigilância Epidemiológica de Violência e Acidentes da Secretaria de Estado da Saúde do Estado de Goiás - SES-GO. (2014b). Cidades em Goiás com maiores índices de mortes por acidente de trânsito. Goiânia. Recuperado em 11 de setembro de 2014, de http://www. saude.go.gov.br/index.php?idMateria=195345

Google Earth. (2015). Localização geográfica de Caldas Novas, Goiás. Recuperado em 20 de setembro de 2015, de https:// www.google.com.br/maps/place/Caldas+Novas,+GO/@$17.724909,-48.6325968,1361 \mathrm{~m} /$ data $=! 3 \mathrm{~m} 1 ! 1 \mathrm{e} 3 ! 4 \mathrm{~m} 2 ! 3 \mathrm{~m}$ 1!1s0x94a736c10eb85f6b:0xb12b7b2d6ed28e1!6m1!1e1

Instituto Brasileiro de Geografia e Estatística - IBGE. (2014). Cidades: Caldas Novas. Rio de Janeiro: IBGE. Recuperado em 10 de setembro de 2014, de http://www.cidades.ibge. gov.br/xtras/perfil.php?lang=\&codmun=520450\&search =goias $\mid$ caldas-novas

Jornal do Sudeste. (2012). Caldas Country Show 2012: drogas, sexo, vandalismo e assassinato. Pires do Rio: Jornal do Sudeste. Recuperado em 12 de março de 2013, de http://www.jornaldosudeste.com.br/jornal2/wp-content/ uploads/2012/11/caldascountry-1facebook-15-11-2012

Lay, M. C. D., \& Reis, A. T. L. (1994). Métodos e técnicas para levantamento de campo e análise de dados: questões gerais. In Anais Workshop Avaliação Pós-Ocupação (p. 201-213). São Paulo: USP.

Lollo, J. A., \& Rohm, S. A. (2005). Aspectos negligenciados em Estudos de Impacto de Vizinhança. Estudos Geográficos, 3(2), 31-45. Recuperado em 10 de julho de 2014, de http://www.rc.unesp.br/igce/grad/geografia/revista/ numero\%206/eg0302jl.pdf 
Moraes, I. R. (2007). 0 processo de urbanização e o estudo de impacto de vizinhança. In Anais do XVI Congresso Nacional do Conselho Nacional de Pesquisa e Pós-Graduação em Direito (p. 1611-1622). Florianópolis: Fundação Boiteux.

Oliveira, C. A., \& Araújo, M. E. Jr (2008). 0 Estudo de Impacto de Vizinhança como instrumento de política urbana. In Anais do XVI Congresso Nacional do Conselho Nacional de Pesquisa e Pós Graduação em Direito (p. 1408-1425). Florianópolis: Fundação Boiteux.

Ornstein, S. (1992). Avaliação pós-ocupação (APO) do ambiente construído. São Paulo: Studio Nobel.

Plano de Gerenciamento de Resíduos Sólidos Caldas Country Show. (2013). Processo n‥ 201300516580 (3o volume, p. 502-520). Caldas Novas - G0: 2ª Vara Cível: Fórum.

Rocco, R. (2009). Estudo de impacto de vizinhança: instrumento de garantia do direito às cidades sustentáveis (2a ed.). Rio de Janeiro: Lumen Juris.

Sánchez, L. E. (2006). Avaliação de impacto ambiental: conceitos e métodos. São Paulo: Oficina de Textos.

Saule, N. Jr, \& Rolnik, R. (2001). Estatuto da Cidade: novos horizontes para a reforma urbana. São Paulo: Pólis.
Secretária de Estado de Gestão e Planejamento de Goiás SEGPLAN. Secretaria de Planejamento e Desenvolvimento. (2003). Quantidade de leitos e hospitais. Caldas Novas - Goiás. Recuperado em 14 de setembro de 2014, de http://www. imb.go.gov.br/down/GoDados2003.pdff

Secretária de Estado de Gestão e Planejamento de Goiás SEGPLAN. Secretaria de Planejamento e Desenvolvimento. (2009). Quantidade de empregos formais no município de Caldas Novas e rendimento médio no período de 1998 a 2000. Recuperado em 14 de setembro de 2014, de http:// www.imb.go.gov.br/down/GoDados2003.pdf

Silva, P. D. O. D'., \& Lollo, J. A. (2013). O Estudo de impacto de vizinhança como instrumento para o desenvolvimento da qualidade de vida urbana. Holos Environment, 13(2), 151-162. Recuperado em 11 de julho de 2014, de http:// www.periodicos.rc.biblioteca.unesp.br/index.php/holos/ article/view/6361

Sundfeld, C. A. (2006). 0 estatuto da Cidade e suas diretrizes. In A. A. Dallari \& S. Ferraz (Coord.). Estatuto da cidade: comentários à Lei 10.257/2001. São Paulo: Malheiros.

Recebido: Nov. 17, 2014

Aprovado: Mar. 04, 2015 